\title{
Incidence and Characteristics of Cataract Surgery in Poland, during 2010-2015
}

\author{
Michał S. Nowak ${ }^{1,2, *(1)}$, Iwona Grabska-Liberek ${ }^{3}$, Katarzyna Michalska-Małecka ${ }^{4}$ (i), \\ Andrzej Grzybowski ${ }^{5,6}$, Milena Kozioł ${ }^{7}$ (D), Wojciech Niemczyk ${ }^{7}$, Barbara Więckowska ${ }^{8}$ \\ and Jacek P. Szaflik ${ }^{9}$ \\ 1 Provisus Eye Clinic, 112 Redzinska str., 42-209 Czestochowa, Poland \\ 2 Saint Family Hospital Medical Center, 19 Wigury str., 90-302 Lodz, Poland \\ 3 Department of Ophthalmology, Centre of Postgraduate Medical Education, 231 Czerniakowska str., \\ 01-416 Warsaw, Poland; iliberek@gmail.com \\ 4 Department of Ophthalmology, School of Medicine in Katowice, Medical University of Silesia, \\ 35 Ceglana str., 40-952 Katowice, Poland; k.michalska.malecka@gmail.com \\ 5 Department of Ophthalmology, University of Warmia and Mazury, 30 Warszawska str., \\ 10-082 Olsztyn, Poland; ae.grzybowski@gmail.com \\ 6 Institute for Research in Ophthalmology, Foundation for Ophthalmology Development, \\ Gorczyczewskiego 2/3, 60-554 Poznan, Poland \\ 7 Department of Analyses and Strategy, Polish Ministry of Health, 15 Miodowa str., 00-952 Warsaw, Poland; \\ m.koziol@mz.gov.pl (M.K.); w.niemczyk@mz.gov.pl (W.N.) \\ 8 Department of Social Insurance, Warsaw School of Economics, 162 Niepodleglosci Ave., \\ 00-001 Warsaw, Poland; bawie@sgh.waw.pl \\ 9 Department of Ophthalmology, SPKSO Ophthalmic Hospital, Medical University of Warsaw, \\ 13 Sierakowskiego str., 03-709 Warsaw, Poland; jacek@szaflik.pl \\ * Correspondence: michaelnovak@interia.pl; Tel.: +48-888-801-010
}

Received: 17 February 2018; Accepted: 28 February 2018; Published: 2 March 2018

\begin{abstract}
Background: To assess the incidence and characteristic of cataract surgery in Poland from 2010 to 2015 and to interpret these findings. Patients and methods: Data from all patients who underwent cataract surgery alone or in combined procedures in Poland between January 2010 and December 2015 were evaluated. Patient data were from the national database of hospitalizations maintained by National Health Fund. Data on the population of Poland were obtained from Central Statistical Office of Poland. Results: In total, 1,218,777 cataract extractions (alone or combined with other procedures) were performed in 1,081,345 patients during 2010-2015. Overall, the incidence of cataract surgery increased from 5.22/1000 person-years in 2010 to 6.17/1000 person-years in 2015. Phacoemulsification was performed in $97.46 \%$ of cataract extractions, and $3.02 \%$ of cataract extractions were combined procedures. The rate of one-day procedures increased from $28.3 \%$ in 2010 to $43.1 \%$ in 2015 . The probability of second-eye surgery 12 months after the first-eye surgery increased from $44 \%$ in 2010 to 73\% in 2015 (log-rank test $p<0.0001$ ). Conclusion: In Poland, from 2010 to 2015, the total incidence of cataract surgery, the number of people who underwent surgery, and the number of one-day cataract surgeries increased significantly.
\end{abstract}

Keywords: eye; cataract; epidemiology; public health

\section{Introduction}

According to the Vision Loss Expert Group, cataract was the leading cause of blindness and the second major cause of moderate and severe visual impairment (MSVI) in 2010. Although the percentage of global blindness and MSVI caused by cataract decreased from $38.6 \%$ to $33.4 \%$ and from $25.6 \%$ to $18.4 \%$, respectively, in 20 years (from 1990 to 2010), barriers to uptake of cataract surgery 
still exist in most countries [1,2]. These reports, had a lack of data from the Eastern European region, including Poland. Poland is the largest eastern European country, with a population of 38 million people in 2011 [3]. Recently published reports by Nowak and Smigielski [4,5] showed that retinal diseases are the major cause of blindness and visual impairment in Poland, as in Western European countries. These reports also revealed that cataract is the second major cause of vision loss in Poland, affecting more than $20 \%$ of people aged 60 years or older.

Globally, the total number of cataract surgeries has increased in all regions, especially in Asia [2]. However, reports on the incidence of cataract surgery based on national basis are limited. In 2011, Behndig et al. [6] reported one million cataract surgeries in Swedish National Cataract Register from 1992 to 2009. In 2015, Daien et al. [7] reported the incidence of cataract surgery in France from 2009 to 2012 was 2.7 million cases. Szigiato et al. [8] published data in 2016 from the Ontario Health Insurance Plan regarding cataract surgeries performed in 2000-2013 in Ontario, Canada. In Poland, health services are free of charge for every citizen and guaranteed by the government and the Polish constitution. The National Health Fund (Narodowy Fundusz Zdrowia (NFZ)) maintains the national database of hospitalizations, which records all medical procedures and provides accurate population-based medical data.

To analyze these data, the Polish Ministry of Health implemented a project titled "Maps of Healthcare Needs-Database of Systemic and Implementation Analyses," which was co-financed by the European Union funds through the European Social Fund under the Operational Program of Knowledge, Education and Development. Our study was part of this project. The aim of the present study was to assess the incidence and characteristic of cataract surgery in Poland from 2010 to 2015 and to interpret these findings.

\section{Material and Methods}

The study design was a retrospective population-based survey. The data from all patients who underwent cataract surgery alone or in combined procedures in Poland between January 2010 and December 2015 were assessed from the national database of hospitalizations [9]. This database is maintained by NFZ, which compiles all data related to hospitalizations in public and private hospitals financed from public sources. The information includes medical data, identification number, date of birth, area code, and sex of patients. The medical data include the diagnoses coded according to the International Classification of Diseases, 10th Revision, and all procedures performed coded using the International Classification of Diseases, 9th Revision (ICD-9) procedure codes and unique NFZ codes corresponding to certain hospital procedures.

For each individual patient, cataract surgery alone or as a combined procedure with corneal transplantation, glaucoma filtrating surgery, or vitrectomy was retrospectively identified. The ICD-9 code 13.4 was used to identify cataract extraction performed by phacoemulsification, with $13.2,13.3$ and 13.5 codes used to identify other types of cataract extractions. The following NFZ codes were used: B12, B13, B14, B15, B18, and B19 corresponding to cataract surgery alone; B04, B05, and B06 corresponding to cataract surgery combined with corneal transplantations; B11 corresponding to cataract surgery followed by glaucoma filtrating surgery; and B16 and B17 corresponding to cataract surgery combined with vitrectomy. The number of one-day procedures was also obtained from the NFZ data. The wait time data and the number of patients waiting for cataract surgery were obtained from the national registry [10].

For statistical analysis, the socio-demographic data of cataract patients including age, sex and place of residence were anonymously recorded. Data regarding the population of Poland were obtained from Central Statistical Office of Poland (Głowny Urzad Statystyczny) [11]. The incidence of cataract surgery was presented for each year separately and by age category matched with corresponding year population data in Poland. The statistical analysis also included the annual volume of cataract surgery, calculations of cataract extractions performed by phacoemulsification, calculations of proportions of one-day and combined procedures, and data regarding the number of cataract surgeries received by 
Polish patients in other European Union countries. The number of patients having cataract surgery in the second eye was collected, and the wait times were calculated. The Kaplan-Meier method was used to calculate the cumulative probability of second-eye cataract surgery during 2010-2015 with a log-rank test to compare the curves between periods. The demographic characteristics of patients are presented with the mean and standard deviation (SD). The study protocol was approved by the Polish Ministry of Health.

\section{Results}

Overall, the incidence of cataract surgery in Poland increased from 5.22/1000 person-years in 2010 to $6.17 / 1000$ person-years in 2015 (Table 1). The incidence of cataract surgery ranged from $0.03 / 1000$ person-years in children to $40.92 / 1000$ person-years in people aged 70 years and older. In total, 1,218,777 cataract extractions (alone or combined with other procedures) in 1,081,345 patients were performed during 2010-2015 (Table 2 and Figure 1).

Table 1. Incidence of cataract surgery in Poland from 2010 to 2015 by age group.

\begin{tabular}{|c|c|c|c|c|c|c|}
\hline & 2010 & 2011 & 2012 & 2013 & 2014 & 2015 \\
\hline No. age $0-18$ years & 7643553 & 7630880 & 7531582 & 7431731 & 7367066 & 7309001 \\
\hline No. of cataract Surgery & 245 & 267 & 272 & 294 & 270 & 242 \\
\hline Incidence/1000 person-years & 0.03 & 0.03 & 0.04 & 0.04 & 0.04 & 0.03 \\
\hline Gender, \% Women & $35.9 \%$ & $41.6 \%$ & $45.6 \%$ & $44.2 \%$ & $46.7 \%$ & $45.5 \%$ \\
\hline No. age 19-39 years & 12482309 & 12523386 & 12461398 & 12355235 & 12201430 & 12015345 \\
\hline No. of cataract Surgery & 1441 & 1305 & 1280 & 1324 & 1383 & 1384 \\
\hline Incidence/1000 person-years & 0.12 & 0.10 & 0.10 & 0.11 & 0.11 & 0.12 \\
\hline Gender, \% Women & $43.9 \%$ & $40.8 \%$ & $40.5 \%$ & $41.5 \%$ & $41.9 \%$ & $41.5 \%$ \\
\hline No. age $40-49$ years & 4792211 & 4822159 & 4838436 & 4879816 & 4956005 & 5064587 \\
\hline No. of cataract Surgery & 3007 & 2680 & 2620 & 2583 & 2849 & 2920 \\
\hline Incidence/1000 person-years & 0.63 & 0.56 & 0.54 & 0.53 & 0.57 & 0.58 \\
\hline Gender, \% Women & $47.4 \%$ & $47.1 \%$ & $47.4 \%$ & $47.9 \%$ & $48.4 \%$ & $49.4 \%$ \\
\hline No. age $50-59$ years & 5770823 & 5765460 & 5656651 & 5536118 & 5406320 & 5245352 \\
\hline No. of cataract Surgery & 15598 & 13397 & 13203 & 13188 & 14645 & 14001 \\
\hline Incidence/1000 person-years & 2.70 & 2.32 & 2.33 & 2.38 & 2.71 & 2.67 \\
\hline Gender, \% Women & $50.6 \%$ & $51.6 \%$ & $51.6 \%$ & $51.5 \%$ & $50.7 \%$ & $51.4 \%$ \\
\hline No. age 60-69 years & 3682048 & 3931289 & 4171206 & 4409809 & 4642821 & 4888294 \\
\hline No. of cataract Surgery & 38973 & 35322 & 37986 & 43120 & 52747 & 57646 \\
\hline Incidence/1000 person-years & 10.59 & 8.98 & 9.11 & 9.78 & 11.36 & 11.79 \\
\hline Gender, \% Women & $60.2 \%$ & $59.7 \%$ & $59.8 \%$ & $59.7 \%$ & $59.6 \%$ & $59.9 \%$ \\
\hline No. age $\geq 70$ years & 4146056 & 3852826 & 3874727 & 3889291 & 3910358 & 3932421 \\
\hline No. of cataract Surgery & 141819 & 122035 & 126644 & 134212 & 156970 & 160905 \\
\hline Incidence/1000 person-years & 34.21 & 31.67 & 32.68 & 34.51 & 40.14 & 40.92 \\
\hline Gender, \% Women & $69.1 \%$ & $68.9 \%$ & $68.5 \%$ & $68.6 \%$ & $68.8 \%$ & $68.4 \%$ \\
\hline No. all & 38517000 & 38526000 & 38534000 & 38502000 & 38484000 & 38455000 \\
\hline No of cataract Surgery & 201083 & 175006 & 182005 & 194721 & 228864 & 237098 \\
\hline Incidence/1000 person-years & 5.22 & 4.54 & 4.72 & 5,06 & 5.95 & 6.17 \\
\hline Gender, \% Women & $65.4 \%$ & $65.1 \%$ & $64.9 \%$ & $65.0 \%$ & $65.1 \%$ & $64.9 \%$ \\
\hline
\end{tabular}

Table 2. Characteristics of cataract surgery in Poland from 2010 to 2015.

\begin{tabular}{cccccccc}
\hline & $\mathbf{2 0 1 0}$ & $\mathbf{2 0 1 1}$ & $\mathbf{2 0 1 2}$ & $\mathbf{2 0 1 3}$ & $\mathbf{2 0 1 4}$ & $\mathbf{2 0 1 5}$ & Al1 \\
\hline $\begin{array}{c}\text { No. of cataract surgery by } \\
\text { surgical technique } \\
\text { phacoemulsification (\%) }\end{array}$ & $\begin{array}{c}193,362 \\
(96.16 \%)\end{array}$ & $\begin{array}{c}169,632 \\
(96.93 \%)\end{array}$ & $\begin{array}{c}177,152 \\
(97.33 \%)\end{array}$ & $\begin{array}{c}190,005 \\
(97.58 \%)\end{array}$ & $\begin{array}{c}224,491 \\
(98.09 \%)\end{array}$ & $\begin{array}{c}233,185 \\
(98.35 \%)\end{array}$ & $\begin{array}{c}1,187,827 \\
(97.46 \%)\end{array}$ \\
\hline $\begin{array}{c}\text { No. of cataract surgery by } \\
\text { surgical technique } \\
\text { extracapsular extraction (\%) }\end{array}$ & $\begin{array}{c}7721 \\
(3.84 \%)\end{array}$ & $\begin{array}{c}5374 \\
(3.07 \%)\end{array}$ & $\begin{array}{c}4853 \\
(2.67 \%)\end{array}$ & $\begin{array}{c}4716 \\
(2.42 \%)\end{array}$ & $\begin{array}{c}4373 \\
(1.91 \%)\end{array}$ & $\begin{array}{c}3913 \\
(1.65 \%)\end{array}$ & $\begin{array}{c}30,950 \\
(2.54 \%)\end{array}$ \\
\hline $\begin{array}{c}\text { No. cataract surgery combined } \\
\text { with corneal }\end{array}$ & $\begin{array}{c}114 \\
\text { transplantation (\%) }\end{array}$ & $\begin{array}{c}186 \\
(0.06 \%)\end{array}$ & $\begin{array}{c}182 \\
(0.10 \%)\end{array}$ & $\begin{array}{c}159 \\
(0.08 \%)\end{array}$ & $\begin{array}{c}187 \\
(0.08 \%)\end{array}$ & $\begin{array}{c}158 \\
(0.07 \%)\end{array}$ & $\begin{array}{c}(0.08 \%) \\
(0.086\end{array}$ \\
\hline
\end{tabular}


Table 2. Cont.

\begin{tabular}{|c|c|c|c|c|c|c|c|}
\hline & 2010 & 2011 & 2012 & 2013 & 2014 & 2015 & All \\
\hline $\begin{array}{l}\text { No. cataract surgery combined } \\
\text { with glaucoma filtration } \\
\text { surgery }(\%)\end{array}$ & $\begin{array}{c}2278 \\
(1.13 \%)\end{array}$ & $\begin{array}{c}2002 \\
(1.14 \%)\end{array}$ & $\begin{array}{c}2175 \\
(1.19 \%)\end{array}$ & $\begin{array}{c}2286 \\
(1.17 \%)\end{array}$ & $\begin{array}{c}2304 \\
(1.01 \%)\end{array}$ & $\begin{array}{c}2049 \\
(0.86 \%)\end{array}$ & $\begin{array}{c}13,094 \\
(1.07 \%)\end{array}$ \\
\hline $\begin{array}{l}\text { No. cataract surgery combined } \\
\text { with pars plana vitrectomy (\%) }\end{array}$ & $\begin{array}{c}2884 \\
(1.43 \%)\end{array}$ & $\begin{array}{c}3199 \\
(1.83)\end{array}$ & $\begin{array}{c}3732 \\
(2.05 \%)\end{array}$ & $\begin{array}{c}4211 \\
(2.16 \%)\end{array}$ & $\begin{array}{c}4381 \\
(1.91 \%)\end{array}$ & $\begin{array}{c}4348 \\
(1.83 \%)\end{array}$ & $\begin{array}{c}227,55 \\
(1.87 \%)\end{array}$ \\
\hline No. of one-day procedures & $\begin{array}{c}56,870 \\
(28.28 \%)\end{array}$ & $\begin{array}{c}59,700 \\
(34.11 \%)\end{array}$ & $\begin{array}{c}67,183 \\
(36.91 \%)\end{array}$ & $\begin{array}{c}72,218 \\
(37.09 \%)\end{array}$ & $\begin{array}{c}93,495 \\
(40.85 \%)\end{array}$ & $\begin{array}{c}102,222 \\
(43.11 \%)\end{array}$ & $\begin{array}{c}451,688 \\
(37.06 \%)\end{array}$ \\
\hline
\end{tabular}

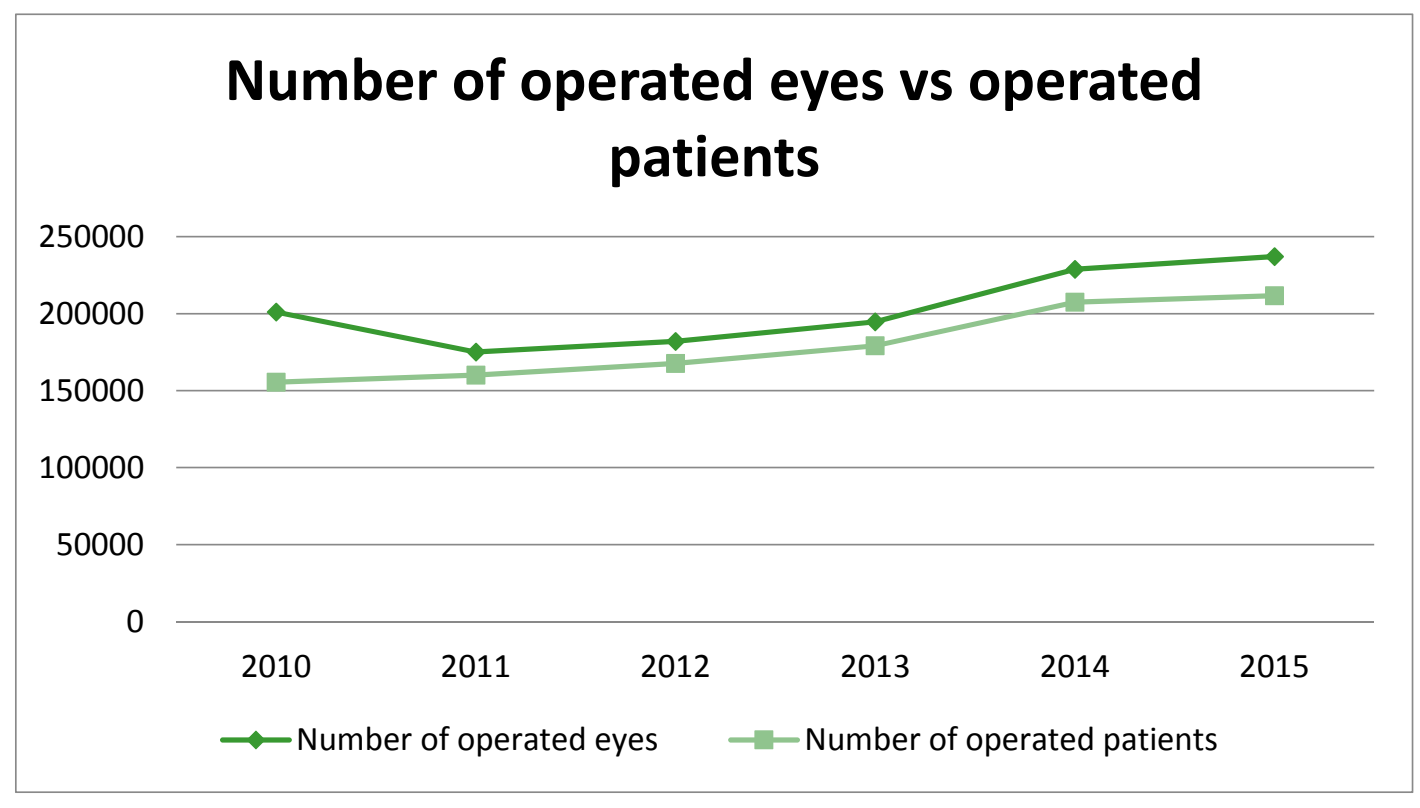

Figure 1. The number of operated eyes vs. operated patients in Poland in 2010-2015.

The number of operated eyes increased by $17.9 \%$ from 201,083 in 2010 to 237,098 in 2015 . However, during 2011-2013, a significant decrease in the number of cataract extractions was observed. In contrast to this finding, the number of operated patients steadily increased between 2010 and 2015 from 155,409 to 211,637, respectively (Figure 1). In the study period, women represented 65.1\% of patients (Tables 1 and 3), and the mean age at surgery was $73.2 \pm 10.2$ years. Young males had relatively more cataract percentage, probably due to traumatic cataract, while older females (i.e., $>70$ years old) had higher cataract surgery population due to the total higher female population as a result of women's longer life expectancy.

Distribution of cataract patients according to the place of residence is presented in Table 3. In Poland $74.6 \%$ of patients who underwent cataract surgery during 2010-2015 lived or had lived in urban areas. However, the availability of cataract surgery for rural residents slightly increased in this period from $24.2 \%$ in 2010 to $27.9 \%$ in 2015. Characteristics of cataract surgery in Poland from 2010 to 2015 are presented in Table 2. 
Table 3. Demographic characteristics of patients who underwent cataract surgery in Poland from 2010 to 2015.

\begin{tabular}{cccccccc}
\hline & $\mathbf{2 0 1 0}$ & $\mathbf{2 0 1 1}$ & $\mathbf{2 0 1 2}$ & $\mathbf{2 0 1 3}$ & $\mathbf{2 0 1 4}$ & $\mathbf{2 0 1 5}$ & All \\
\hline Age mean \pm SE & $73.1 \pm 10.3$ & $73.0 \pm 10.4$ & $73.2 \pm 10.4$ & $73.2 \pm 10.3$ & $73.4 \pm 10.1$ & $73.4 \pm 10.0$ & $73.2 \pm 10.2$ \\
\hline Women & 131,548 & 113,938 & 118,108 & 126,564 & 148,949 & 153,913 & 794,020 \\
$(\%)$ & $(65.42 \%)$ & $(65.10 \%)$ & $(64.89 \%)$ & $(65.00 \%)$ & $(65.08 \%)$ & $(64.91 \%)$ & $(65.15 \%)$ \\
\hline Men & 69,535 & 61,068 & 63,897 & 68,157 & 79,915 & 83,185 & 424,757 \\
$(\%)$ & $(34.58 \%)$ & $(34.90 \%)$ & $(35.11 \%)$ & $(35.00 \%)$ & $(34.92 \%)$ & $(35.09 \%)$ & $(34.85 \%)$ \\
\hline Urban residence & 152,418 & 130,039 & 134,501 & 143,495 & 166,508 & 171,005 & 897,966 \\
$(\%)$ & $(75.80 \%)$ & $(74.30 \%)$ & $(73.90 \%)$ & $(73.70 \%)$ & $(72.75 \%)$ & $(72.12 \%)$ & $(74.58 \%)$ \\
\hline Rural residence & 48,665 & 44,967 & 47,504 & 51,226 & 62,356 & 55,093 & 309,811 \\
$(\%)$ & $(24.20 \%)$ & $(25.70 \%)$ & $(26.10 \%)$ & $(26.30 \%)$ & $(27.25 \%)$ & $(27.88 \%)$ & $(25.42 \%)$ \\
\hline
\end{tabular}

Phacoemulsification was performed in $97.46 \%$ of cataract extractions. The use of extracapsular lens extraction decreased from $3.84 \%$ in 2010 to $1.65 \%$ in 2015 . During the analyzed period, $3.02 \%$ of cataract extractions were combined procedures. The number of combined procedures increased by $15 \%$ between 2010 and 2015, and the highest number was observed in 2014 . The majority of cataract extractions were combined with vitrectomy $(61.77 \%)$, followed by glaucoma filtrating surgery $(35.55 \%)$ and corneal transplantation (2.68\%). In total, 22,755 phacovitrectomies were performed during 2010-2015, which represented $1.87 \%$ of all cataract procedures in this period. Cataract extractions combined with glaucoma surgery were reported in 13,094 eyes (1.07\% of all cataract procedures during 2010-2015), and corneal transplants combined with cataract surgery were performed in 986 eyes $(0.08 \%$ of all cataract procedures during $2010-2015)$. In the study period, $37.1 \%$ of cataract surgeries were one-day procedures in Poland (Table 2). However, the rate of one-day procedures significantly increased from $28.3 \%$ in 2010 to $43.1 \%$ in 2015. Nationwide data on the number of people waiting for cataract surgery and on wait times in Poland were available from December 2014. In total, 539,019 persons were waiting for cataract surgery in December 2015, and this number had increased by $7 \%$ from December 2014. These numbers mean that mean and median wait times for cataract surgery on December 2015 were 326 and 188 days, respectively (Figure 2). However, the probability of second-eye surgery 12 months after the first-eye surgery increased from $44 \%$ in 2010 to $73 \%$ in 2015 (log-rank test $p<0.0001$ ). The Kaplan-Meier analysis showing the probability of second-eye surgery in Poland between 2010 and 2015 is presented in Figure 3.

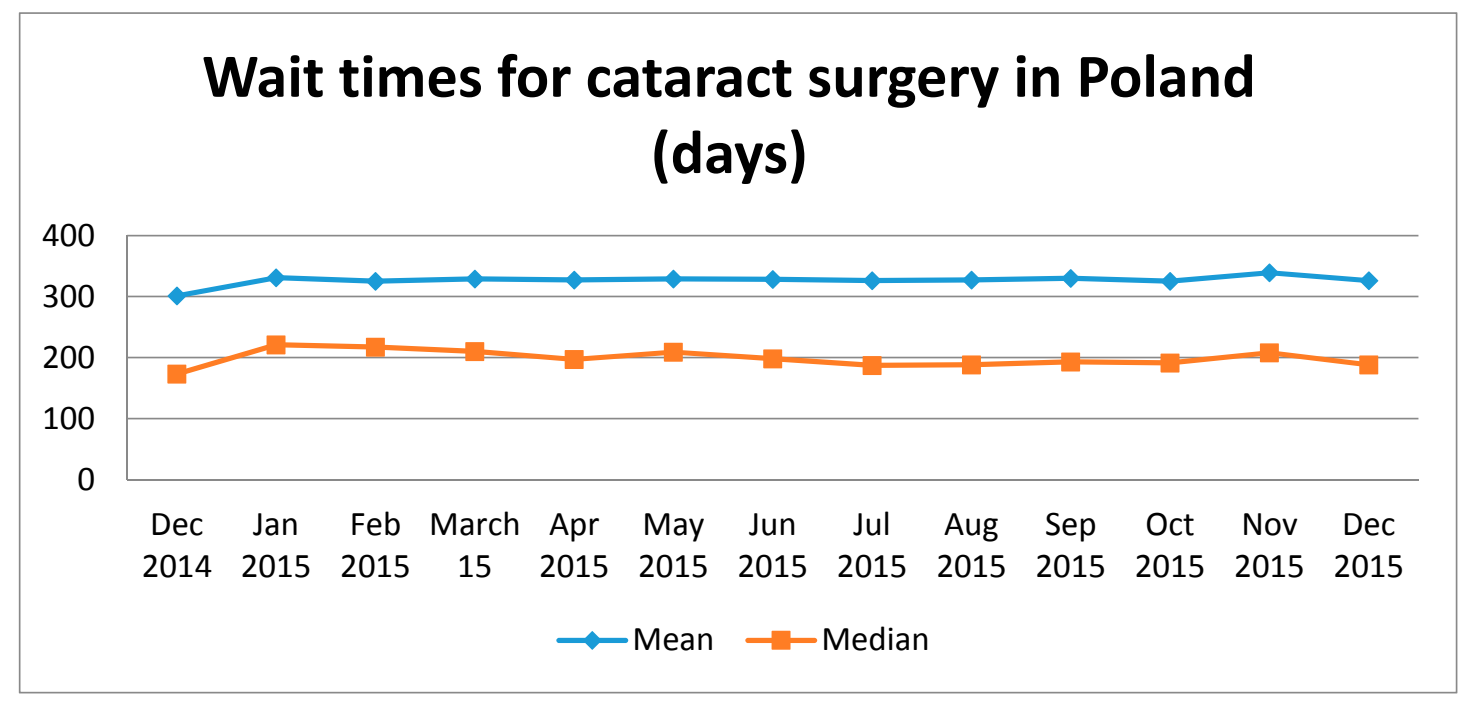

Figure 2. Wait times for cataract surgery in Poland. 


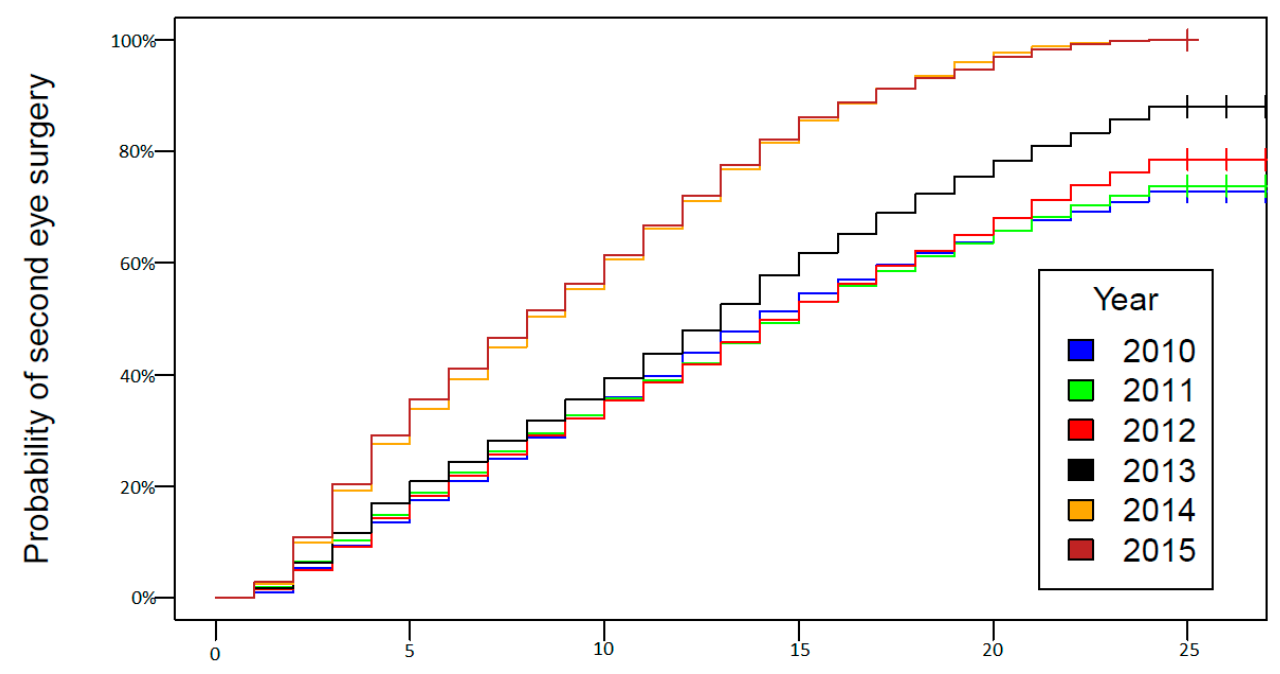

Time after first eye surgery (mo)

Figure 3. The Kaplan-Meier analysis showing the probability of second-eye surgery in Poland in 2010-2015.

In November 2014, the Polish government introduced the European Union Directive on the application of patients' rights on cross-border health care. From November 2014 to December 2015, 4542 Polish patients had cataract surgery in other European Union countries [12]. Ninety-five percent of them had cataract surgery in Czech Republic, and the remaining patients received care in Germany, Latvia, and Slovak Republic.

\section{Discussion}

This study provides for the first time data concerning the incidence and characteristics of cataract surgery from the Eastern European region. The study describes trends of cataract surgery and age-specific rates of the incidence of cataract surgery in the overall population of Poland during 2010-2015. During the study period, the incidence of cataract surgery in Poland increased from $5.22 / 1000$ person-years in 2010 to $6.17 / 1000$ person-years in 2015, with a significant decrease during 2011-2013. This decrease was mainly attributable to the reduction in the reimbursement cost of cataract surgery procedure from the NFZ for public and private hospitals. The hospitals had to reorganize their ophthalmology departments and cut the surgery costs. Afterwards, a significant increase in the number of cataract extractions was observed. Our trends agree with the results of previous studies from Western countries that showed a significant increase in the incidence of cataract surgery over time. The incidence of cataract surgery in Sweden increased from 4.47/1000 person-years in 1992 to $9.0 / 1000$ person-years in 2009 [6]. In comparison, the incidence of cataract surgery in Ontario increased from 7.3/1000 person-years in 2000 to 10.5/1000 person years in 2012; in Minnesota, USA, from 8.5/1000 person-years in 2005 to 11.0/1000 person-years in 2011; and, in France, from 9.86/1000 person-years in 2009 to $11.08 / 1000$ person-years in 2012 [7,8,13]. The overall incidence of cataract surgery per 1000/person-years in Poland was significantly lower than in Sweden, France, Canada, and the United States. However, strong associations of socioeconomic indices with quantity and quality of cataract surgery persists throughout the world [2,14]. Poland is a middle-income country and spends much less money on health care than Western countries [11]. Nevertheless, we found that the probability of second-eye surgery 12 months after the first-eye surgery increased during the research period from $44 \%$ to $73 \%$, which is higher than in France but lower than in the United States $[7,13]$. In the present analysis, women represented $65.1 \%$ of the patient population. Other studies also noted a difference in surgical rate by sex. The proportion of women who underwent 
cataract extraction was 61\% in Sweden, 59\% in France, and it was also significantly higher than in men in Minnesota $[6,7,13]$. Globally, women have higher rates of blindness and moderate and severe visual impairment (MSVI) caused by cataract compared with men, and sex inequity in cataract surgery persists in low- and middle-income countries, where men are 1.71 times more likely to have cataract surgery than women [2]. Despite the decline in the prevalence of blindness and MSVI caused by cataract, it was still the main cause of blindness and the second most common cause of MSVI in $2010[1,2]$. This outcome was mainly the result of the rapid aging of populations [2,7]. In the present study and in previously published studies, the incidence of cataract surgery increased in older age groups [7,15-17]. In Poland, only $0.1 \%$ of all cataract surgeries were pediatric cases. In the present study the mean age at cataract surgery was $73.2 \pm 10.2$ years. In other studies, the mean age for cataract surgery was 73.4 years in France in 2012, 73.0 years in Minnesota in 2011, and 74.9 years in Sweden in $2009[6,7,13]$. During the study period, a low number of cataract surgeries were performed as a one-day procedure in Poland. During 2010-2015, only 37.1\% of cataract surgeries were one-day procedures, which placed Poland, together with Romania, Croatia and FYR of Macedonia, among the OECD countries with the lowest number of one-day procedures in cataract surgery [18]. At the same time, in many Western European countries and in some Eastern European countries, such as Estonia and Slovenia, the rate of one-day procedures in cataract surgery was over 95\% [18]. However, the rate of one-day procedures in Poland significantly increased from $28.3 \%$ in 2010 to $43.1 \%$ in 2015, which is a desired trend. No bilateral cataract surgery was officially reported during 2010-2015 in the NFZ database, mainly due to lack of legal regulations in this matter, which were introduced in January 2017. The use of phacoemulsification occurred in $97.46 \%$ of cataract extractions in Poland in 2010-2015. The use of this technique was lower than in France, but it was significantly higher than in other low- and middle-income countries $[7,19]$. The use of extracapsular lens extraction decreased from $3.84 \%$ in 2010 to $1.65 \%$ in 2015 ; however, it remains useful for some patients. The total number of cataract extractions combined with other procedures (vitrectomy, glaucoma filtrating surgery and corneal transplantation) in Poland increased by 15\% between 2010 and 2015. It is likely that these increases might have been related to the changes in the approach to vitreoretinal diseases. Combined phacovitrectomy has been reported to be significantly less costly to Medicare in the United States than a two-step approach for patients with an indication for vitrectomy and a visually significant cataract [20]. During the study period, $74.6 \%$ of patients who underwent cataract surgery in Poland lived in urban areas. A barrier for cataract surgery for rural residents was the low distribution of ophthalmologists across some regions. Other barriers for regularly performing cataract surgery in Poland included insufficient financing from the NFZ and other social, infrastructural, and geographic factors, which resulted in patients seeking care elsewhere in the country as well outside Poland [12]. From November 2014 to December 2015, 4542 Polish patients had cataract surgery in other European Union countries. All of them had their surgery costs reimbursed by Polish NFZ due to the European Union Directive on the application of patients' rights on cross-border healthcare [12].

Limitations of the present study include possible presence of misclassification or biases related to under-detection. Errors in using specific ICD-9 and NFZ codes might have occurred at different levels (operating theaters, hospitals, and NFZ offices), but such mistakes likely had only a minor impact on the study findings. Our study was country based and covered the overall population of Poland. The population size, national recruitment and impact of its findings on public health are the most important strengths of the current study. However, our results are specific to the Polish health care system only and cannot describe other health care systems in Eastern Europe. It would be also beneficial to have data on the outcomes of cataract surgery in the future, because nowadays these data are not collected in the national database of hospitalizations.

\section{Conclusions}

In conclusion, this study reported the incidence and characteristics of cataract surgery in the overall population of Poland during 2010-2015. There were very positive trends in cataract surgery 
during these years. Despite the decrease in the number of operated eyes during 2011-2013, from 2010 to 2015 the total incidence of cataract surgery significantly increased, as did the number of people who underwent surgery, and the number of one-day cataract surgeries. In addition, the probability of second-eye surgery 12 months after the first-eye surgery increased from $44 \%$ in 2010 to $73 \%$ in 2015 . Nevertheless, few Polish patients had cataract surgery abroad.

Acknowledgments: The present study was co-financed by the European Union funds through the European Social Fund under the Operational Program of Knowledge, Education and Development. EU grant number: POWR 05.02.00-00-0149/15-01.

Author Contributions: Michal S. Nowak conceived and designed the experiments. Data were collected by Milena Koziol and Wojciech Niemczyk. The results were analyzed by Michal S. Nowak, Iwona Grabska-Liberek, Katarzyna Michalska-Malecka and Barbara Wieckowska. The first and final drafts were written by Michal S. Nowak. The defects of the drafts were critiqued by Jacek P. Szaflik and Andrzej Grzybowski. All authors agreed on the final draft of this study.

Conflicts of Interest: The authors declare no conflict of interest.

\section{References}

1. Bourne, R.R.; Stevens, G.A.; White, R.A.; Smith, J.L.; Flaxman, S.R.; Price, H.; Jonas, J.B.; Keeffe, J.; Leasher, J.; Naidoo, K.; et al. Vision Loss Expert Group. Causes of vision loss worldwide, 1990-2010: A systematic analysis. Lancet Glob. Health 2013, 1, e339-e349. [CrossRef]

2. Khairallah, M.; Kahloun, R.; Bourne, R.; Limburg, H.; Flaxman, S.R.; Jonas, J.B.; Keeffe, J.; Leasher, J.; Naidoo, K.; Pesudovs, K.; et al. Vision loss expert group of the global burden of disease study. Number of people blind or visually impaired by cataract worldwide and in world regions, 1990 to 2010. Investig. Ophthalmol. Vis. Sci. 2015, 56, 6762-6769. [CrossRef] [PubMed]

3. The National Census of Population and Housing 1 April-30 June 2011. Zakład Wydawnictw Statystycznych. Warszawa 2013. Available online: http:/ / www.stat.gov.pl/gus/nsp (accessed on 21 August 2017).

4. Nowak, M.S.; Smigielski, J. The prevalence and causes of visual impairment and blindness among older adults in the city of Lodz, Poland. Medicine 2015, 94, e505. [CrossRef] [PubMed]

5. Nowak, M.S.; Smigielski, J. The prevalence of age-related eye diseases and cataract surgery among older adults in the city Lodz, Poland. J. Ophthalmol. 2015, 2015, 605814. [CrossRef] [PubMed]

6. Behndig, A.; Montan, P.; Stenevi, U.; Kugelberg, M.; Lundström, M. One million cataract surgeries: Swedish National Cataract Register 1992-2009. J. Cataract Refract. Surg. 2011, 37, 1539-1545. [CrossRef] [PubMed]

7. Daien, V.; Le Pape, A.; Heve, D.; Carriere, I.; Villain, M. Incidence and characteristics of cataract surgery in France from 2009 to 2012: A national population study. Ophthalmology 2015, 122, 1633-1638. [CrossRef] [PubMed]

8. Szigiato, A.A.; Trope, G.E.; Jin, Y.; Buys, Y.M. Wait times and volume of cataract surgery in Ontario: 2000-2012. Can. J. Ophthalmol. 2016, 51, 7-13. [CrossRef] [PubMed]

9. The National Health Fund Data. 2017. Available online: http:/ / www.nfz.gov.pl (accessed on 21 August 2017).

10. The National Registry Data. 2017. Available online: http:/ / www.kolejki.nfz.gov.pl (accessed on 21 August 2017).

11. Central Statistical Office of Poland Data. Available online: http://www.stat.gov.pl (accessed on 21 August 2017).

12. Grzybowski, A.; Maciejewski, A. Wzrost liczby operacji usuniecia zacmy wykonywanych $w$ ramach dyrektywy transgranicznej w $2016 \mathrm{r}$. [Increase in the number of cataract surgeries performed under the cross-border directive in 2016]. Ophthatherapy 2017, 4, 10-14. [CrossRef]

13. Gollogly, H.E.; Hodge, D.O.; St Sauver, J.L.; Erie, J.C. Increasing incidence of cataract surgery: Population-based study. J. Cataract Refract. Surg. 2013, 39, 1383-1389. [CrossRef] [PubMed]

14. Wang, W.; Yan, W.; Muller, A.; He, M. A global view of output and outcomes of cataract surgery with national indices of socioeconomic development. Investig. Ophthalmol Vis. Sci. 2017, 58, 3669-3676.

15. Klein, B.E.; Klein, R.; Moss, S.E. Incident cataract surgery: The Beaver Dam Eye Study. Ophthalmology 2007, 104, 573-580. [CrossRef]

16. Panchapakesan, J.; Mitchell, P.; Tumuluri, K.; Rochtchina, E.; Foran, S.; Cumming, R.G. Five year incidence of cataract surgery: The Blue Mountains Eye Study. Br. J. Ophthalmol. 2003, 87, 168-172. [CrossRef] [PubMed]

17. Park, S.J.; Lee, J.H.; Kang, S.W.; Hyon, J.Y.; Park, K.H. Cataract and cataract surgery: Nationwide prevalence and clinical determinants. J. Korean Med. Sci. 2016, 31, 963-971. [CrossRef] [PubMed] 
18. Health at a Glance: Europe 2016. Joint Publication of OECD and the European Commission. 2016. Available online: http:/ / www.oecd.org/health/health-at-a-glance-europe-23056088.htm (accessed on 21 August 2017).

19. Hashemi, H.; Fotouhi, A.; Rezvan, F.; Gilasi, H.; Asgari, S.; Mohazzab-Torabi, S.; Etemad, K.; Yekta, A.; Khabazkhoob, M. Trends in outpatient cataract surgery in the Islamic Republic of Iran, 2006-2010. East Mediterr. Health J. 2016, 22, 676-681. [CrossRef] [PubMed]

20. Seider, M.I.; Michael Lahey, J.; Fellenbaum, P.S. Cost of phacovitrectomy versus vitrectomy and sequential phacoemulsification. Retina 2014, 34, 1112-1115. [CrossRef] [PubMed] 